\title{
Analysing Social Values in Identification : A Framework for Research on the Representation and Implementation of Values
}

\section{Menard, Rusten}

2016-06

\begin{abstract}
Menard, R 2016 , ' Analysing Social Values in Identification : A Framework for Research on the Representation and Implementation of Values ' , Journal for the Theory of Social Behaviour, vol. 46 , no. 2 , pp. 122-142 . https://doi.org/10.1111/jtsb.12087
\end{abstract}

http://hdl.handle.net/10138/236337

https://doi.org/10.1111/jtsb.12087

acceptedVersion

Downloaded from Helda, University of Helsinki institutional repository.

This is an electronic reprint of the original article.

This reprint may differ from the original in pagination and typographic detail.

Please cite the original version. 


\title{
Analysing social values in identification; a framework for research on the representation and implementation of values
}

Accepted version for Journal for the Theory of Social Behaviour, 46(2), 122-142.

Rusten Menard

University of Helsinki, Department of Social Research

\begin{abstract}
This article contributes to the concept of social values by presenting analytical tools that explore how social values are classified, re-presented and interpersonally performed in the construction of identities. I approach social values as classificatory systems of acceptability and desirability that are collectively generated. The meanings of social values are embedded in culture and in power imbalanced social relations; they constantly undergo reformulation in identification processes and are also used to define the social order. I suggest that social values can be analysed in relation to aspects of representation and interpersonal positioning that are also involved in the construction of identities: Value classifications involve compartmentalising moral orders into e.g. good, desirable, important, necessary; value projects are concerned with how value classifications and content occupy roles and become oriented to action; and value positioning is concerned with how narrators align with value classifications and projects as well as with individuals and groups seen to share or reject such classifications and projects.
\end{abstract}

Keywords: values, identification, subject position, classification, representation, positioning 


\section{INTRODUCTION}

Theory and research on values is longstanding, diverse and vast. However, frameworks that approach values as culturally embedded and collectively generated structures that are continuously reshaped and implemented in identification processes are lacking. In this article I present tools for analysing social values based on how they are classified, re-presented and performed in the discursive construction of identities.

Values have generally been treated in the social sciences as either macrostructures that impinge themselves upon individuals similarly to norms (Sulkunen \& Törrönen, 1997), or as cognitive structures that individuals choose and apply in various contexts (Tsirogianni \& Gaskell, 2011). The dominant contemporary research paradigm on values in psychology and social psychology is positivist, involving primarily quantitative methodologies. Values are defined abstractly and approached as universally structured and relatively stable guiding principles for what people consider important in life (e.g., Schwartz, 1992). Contemporary research on values is thus founded on older paradigms from the human sciences: The means by which social interactions come about originate in individual cognition and emotions (Harré, 2001). Research methods are directed to finding individual cognitive mechanisms behind patterns of behaviour and interaction (Harré, 1999). Results are often prematurely and over generalised (Harré et al., 2009).

That research on values has remained in the old paradigm is evidenced by the lack of studies addressing how values are contextually shaped and implemented in pluralistic, power imbalanced social spaces. Sowińska (2013) points out that although values are presumed to be integral to building ideologies in critical discourse studies, value meanings have been taken for granted or left implicit in critical discourse-analytic research. Also, with alternative psychologies that take as their focus the construction of meaning in interaction—such as discursive psychology and dialogical approaches within social representations theory—the theorisation of value formation and analyses of value meanings has been overlooked. Discourse analysis emerged within psychology out of the need for alternatives to cognitive reductionism and its accompanying quantitative and experimental 
methodologies; it thus emphasises the action-orientation of discourse and representations (Potter $\&$ Wiggins, 2008, p. 74). Research on values has thus far not taken advantage of discourse analytic approaches and other alternatives to old-paradigm psychology and social psychology.

This paper outlines a framework for examining social values as culturally embedded and collectively generated structures that are continuously reshaped and implemented in lived realities (cf. Tsirogianni \& Gaskell, 2011; Tsirogianni \& Sammut, 2014). As a starting point, it is useful to note that social values emerge differently for people with differing interests and life experiences, and in different areas of social life (van Dijk, 1998, p. 77). The emphasis in this paper is thus on the context specificity of social values and on how they emerge in constructions of identities. The aim is therefore to develop a research methodology that better accommodates situated meanings, how those meanings are oriented to action, and what is accomplished with those meanings.

My approach looks at value emergence from a critical dialogic perspective. Classifications, representations and performances of social values always occur in relation to previous discourses and within complex and specific relations of domination (cf. Bakhtin, 1981). Social values are part of shared culture and are fundamental in building and maintaining ideologies, while acting as reference points for social and cultural evaluation (van Dijk, 1998, pp. 74-77). Values not only reflect the social order, but constitute a form of social ordering. In Bourdieuian terms (e.g., Bourdieu, 1984) values are used to differentiate (elevate and subordinate) between the social and cultural practices — and therefore the values — of one social class and another. Social values that serve in constructing and sustaining ideologies can be implemented as tools for evaluating and positioning others and their perceived practices and values.

One way of deepening our understanding of the concept of social values is by developing empirical tools for unravelling how classifications and representations emerge as values and how they are used to construct and distinguish identities. Such tools would help us explore how consistent these social value formulations are with the ideologies and dominating inter-group 
relations that they reference. The framework that I develop in this paper explicates social values in relation to how they are classified and conceptualised. It also explicates how social values are performed as speakers and writers position themselves in relation to those classifications and representations, as well as in relation to others and their perceived values.

\section{TOWARDS A FRAMEWORK FOR RESEARCH ON SOCIAL VALUES IN IDENTIFICATION}

Tsirogianni and colleagues (Tsirogianni \& Gaskell, 2011; Tsirogianni \& Sammut, 2014) describe social values as socially generated beliefs and systems of beliefs that gain meaning in relation to desire, moral imperatives and importance. Social values are conveyed through particular viewpoints and play a part in ordering the social sphere in terms of what can legitimise and sustain collective identities. As part of the family of social representations, social values can affect individual choices while also being contested and collectively transformed. Intersecting with identification, they are ongoing processes of meaning-making that guide presentations of the self and action. Social values are continuously reformulated as individuals move through various contexts formulating multiple identities. The authors suggest that a better understanding of social values could proceed from distinguishing between value conceptions and implementations, and by considering how social values might intersect with identities.

Following Stuart Hall (1996, p. 14), I understand identification as a process by which subjects endlessly assume, dissociate from and perform the positions to which they are summoned. I approach identities in this article as subject position constructions, which show continuity yet are at the same time decentred, multiple and never complete (Törrönen, 2001). The manner in which we take up and elaborate subject positions is discursive, interacting with both previous life experiences and temporally immediate contexts and imaginary social orders. Discursive events always involve both reconstructions of social reality that occur through categorisation and the production of storylines, and the positioning of oneself and others in relation to those categories and storylines 
(Davies \& Harré, 1990; van Langenhove \& Harré, 1994, pp. 362-363). Positioning theory approaches identification in relation to how systems of categories are given meaning and are structured, as well as to how they impinge upon intrapersonal, interpersonal, and intergroup action through negotiations of rights, duties, competencies and obligations (Harré \& van Langenhove, 1999). Positioning entails learning culturally salient categories and discursively developing moral orders that are constructed around belonging in the world in particular ways, from a particular perspective and understanding of the local expressive order (Davies \& Harré, 1990). Identification is thus a matter of the selection, evaluation and positioning of content, and the evaluation and positioning of oneself and others in relation to that content.

A positioning theorist's approach to subject positions is compatible with how evaluation is explicated by discourse analysts informed by systemic functional linguistics. Martin and White (2005) approach evaluation in terms of the attitudinal and intersubjective resources of language. The expression of attitudes can reveal values and be related to how authors construct their own and their putative audiences' status or authority. Intersubjective resources enable speakers and writers to position the values and content referenced in communication, as well as that of others and of their perceived viewpoints. The authors explain intersubjective resources in relation to Vološinov/Bakhtin's dialogism. In text production, speakers and writers to greater or lesser extents reference and reformulate previous utterances, values and viewpoints around the same issue. They also align or disalign with those utterances, values and viewpoints and in doing so, they negotiate communities of shared values and identities.

The tools that I develop in this paper for analysing social values in identification proceed firstly from the compatibility and similarities in the discussions of positioning theorists and systemic linguists regarding the interplay between the construction of meaning and the evaluations and values involved therein, and the positioning of oneself and others in relation to those meanings. This is fundamentally an interplay between the realms of representation and interaction. The 
framework is also informed by Törrönen's $(2001 ; 2014)$ delineation of the manner in which this interplay between representational and interpersonal realms occurs in identification processes. Understanding this delineation together with the above discussions creates an opening for exploring how social values emerge, take form and are implemented in identification.

Törrönen $(2001 ; 2014)$ defines identification in relation to interactive yet empirically separable aspects of representation and interpersonal positioning. Embedded in the framework is also a commentary on the production of values in discourse (Sulkunen \& Törrönen, 1997). In representational aspects of identification, classifications partition moral orders by drawing boundaries between 'us' and 'them'. As storylines are built these classifications are positioned into participant roles and oriented towards an action goal. In the interpersonal realm, classifications and participant roles are articulated into structures of viewpoint and interactive positioning. (Törrönen, 2001; 2014.) As with positioning theory and systemic linguistic theories of evaluation, identification in this framework involves speaker or writer orientation towards classifications and content as well as towards others and their viewpoints. Törrönen's framework additionally implicates the classification, elaboration and implementation of values in the construction of identities. This occurs firstly in how 'our' rationalities, competencies, passions, aesthetics, tastes and so on are classified in opposition to 'theirs'. Value projects are elaborated as value classifications and contents occupy participant roles in the building of storylines. In interpersonal aspects of identification, values are positioned onto the viewpoints of oneself and others.

\section{SOCIAL VALUES AS VALUE CLASSIFICATIONS, VALUE PROJECTS AND VALUE POSITIONINGS}

I define social values as collectively generated classificatory systems of acceptability and desirability that are embedded in culture and in power imbalanced social relations, always undergoing reformulation in identification, and used to define the social order. According to this definition and taken together with the above discussions, social values can be specified and 
analysed in relation to the representational aspects of value classifications and value projects, and the interpersonal aspects of value positionings. Although empirically distinguishable, in speech and text production these aspects overlap and are inseparable.

The meanings of social values are built from evaluations and classifications, which occur in relation to previous meanings, subject positions and discourses. Value classification involves drawing conceptual boundaries in representation and compartmentalising moral orders in relation to speakers' and writers' interpretations of the good, desirable, important, necessary, and so on. Moscovici (1961/2008) describes classification in social representation as the insertion of an unfamiliar phenomenon or concept into systems of categories that already exist, a process which may also disrupt previous codes and transform relations. The function of classification in social representation is to draw boundaries between 'us' and 'them', and to territorialise values. (Moscovici, 1961/2008, pp. 70-72, 105, 180; see also Howarth, 2006; Jodelet, 1991.) Bourdieu (e.g., 1977) describes the classification process as reliant upon individuals' embodiment of social structures that have been imbued with meaning throughout the course of a collective history. In developing cultural competence these social structures are negotiated and internalised in particular ways by individuals occupying positions in various social classes. The internalisation of social structures enables individuals to classify for practical purposes, in the course of everyday practices and consumption. Classification is a means of evaluating and distinguishing the practices of oneself from the practices and tastes of others. It works to update and sustain relations of domination and hierarchical social class structures. (Bourdieu, 1977, pp. 466-484.) Categorisation in speech and text production is therefore never neutral; it is bound to the elaboration of values in representation and identification. Classification involves a compartmentalisation of symbolic orders and a territorialisation of tastes and values.

The construction of value projects concerns how classifications and contents that are emerging in representations of social values are positioned into roles and oriented to action. 
Vološinov (1929/1986, p. 105) describes the construction of meaning as motivated, reflecting the interests of social groups, and as being shaped dialectically through value judgements. Whether the topic is music or foreign policy, the construction of meaning and identities is formed discursively, in the living process. It also entails categorising and conceptualising the rights, duties and competencies of oneself and others (Harré \& van Langenhove, 1991). Value projects are built in relation to ideologies and previous life experiences by narrators qualifying the constituting elements of social values in relation to desire, obligation, ability and competency (cf. Törrönen, 2001). Value projects reflect how the meanings of social values are formed as speakers or writers build storylines and position value classifications, events, and human and non-human actors into action-oriented participant roles.

Lastly, we use language to orient ourselves to our addressees as well as to orient to our own and others' speech and texts (Lemke, 1998). Elaborations of subject positions involve positioning oneself and others in terms of the categories and storylines unfolding in conversations (Davies \& Harré, 1990). In value positioning, narrators align and disalign with value classifications and projects as well as with the individuals and groups believed to be sharing and rejecting them. Value positioning is the performative aspect of social values and is the aspect most closely tied to their implementation in identification. Speakers and writers implement social values by bringing various viewpoints inside the boundaries of their moral orders and taking distance from others, thereby positioning themselves and their putative audiences in terms of the content of communication. Thus in conceptualising and articulating social values, narrators are not merely classifying and sharing information about their desires, passions, obligations, expectations, imaginaries, morals and so on; they are also often implicitly or explicitly inviting others to join the value project and to align with and share its associated values (cf. Martin \& White, 2005, p. 95; Törönen, 2003). 


\section{DATA AND METHODS}

The data used to further develop and demonstrate the framework for analysing social values comes from a study dealing with values and positioning in the discursive construction of cultural and societal identities (cf. Törrönen, 2014). One of my main aims in this study was to examine how socially salient values are given meaning and performed in various contexts, and amongst people who may have substantially different relations to particular norms.

The participants in the study come from three Finnish study populations: people contacted through a random sample obtained from the Finnish Population Register Centre, people with transgendered life experiences, and people diagnosed with Asperger's syndrome. ${ }^{1}$ These groups provide an interesting comparison for exploring how values can take shape amongst people who are positioned differently in relation to gender norms and norms of social interaction. ${ }^{2}$ The data consist of written interviews in which participants were asked to give and explain their own opinions to the following questions: Are people basically the same or basically different?; What types of people and groups of people do you like and what types do you not like?; What are the advantages or disadvantages of minorities living in Finland (for example the Sami, Swedish-speaking Finns, homosexuals, Muslims)?; What are Roma beggars doing in Finland?; Please complete the following sentence in your own words: The social structure in Finland is...; Is the Finnish state fair?; Does everyone have equal opportunities to realise their goals?; Do you see yourself belonging to any social strata, classes, components or comparable groups? ${ }^{3}$

\section{ANALYSING VALUE CLASSIFICATIONS IN SOCIAL VALUES}

In adopting a position, speakers categorise their own and others' perceived personal and moral characteristics, such as those related to dominance and submission, competence and incompetence, fairness and unfairness, and so on (Harré \& van Langenhove, 1991). In addition to categorisations of 'us' and 'them', positioning also involves classifying and describing those aspects of the social world that are under discussion (van Langenhove \& Harré, 1994). An analysis of value 
classifications focuses on the categories in speech and texts that speakers and writers associate with goodness, importance, duty, responsibility, normality and so on. We can understand value classifications occurring as representations of the social sphere and 'us' and 'them' are recontextualised in specific communicative events, where recontextualisation is the process by which representations of one type of social practice (e.g., neo-capitalism) are incorporated into another (e.g., research) and filtered; this process may include prioritising, deleting, abstracting, adding or differently arranging its elements (Fairclough, 2003, p. 139). Value classifications therefore always occur in interaction with real or imagined others, previous texts, subject positions and discourses.

Value classifications can be analysed by considering speakers' and writers' evaluations and attitudinal expressions (cf. Fairclough, 2003, pp. 171-173; Martin \& White, 2005, pp. 42-91). Value classifications can be triggered by, for example, evaluative assertions (e.g., "Working is important"), deontic modalisations (e.g., "People should work"), and affective evaluations (e.g., "I enjoy working”). Value classifications can also surface in communication indirectly as assumptions (cf. Fairclough, 2003, pp. 57, 173), or through the particular selection of content in representation (cf. Martin \& White, 2005, pp. 61-68). These are much less transparent commitments to values that are more deeply embedded in value systems and discourses. They do not typically have explicit linguistic triggers. In order to recognise these indirect value classifications, addressees or researchers analysing texts often need to rely on their own cultural knowledge.

Let us examine the value classifications in Text 1 , which was written by a respondent from the random sample.

\section{Text 1}

I consider all groups of people of equal value. I don't want to distinguish people based on colour or continent. [...] I think people are basically the same, no matter where they are from. [...] Not everyone thinks in the same way as me. I don't like people who entitle themselves to act differently than [what] my morality is. For example, in some cultures a woman's status is weak and I don't understand that. I wouldn't want to be treated like that. I'm happy that I was born a Finn. Even though I try to see the good in everyone, I can't help that I am almost racist when I think about the rights of women and children. (Participant number 136, Female) 
Multiple value classifications emerge in Text 1 . The writer begins by making classifications in relation to the equality ([line/s] 1) and sameness (2) of people. Taking these classifications together with the writer's articulation of not wanting to distinguish between people (1-2), 'equal treatment' can be marked as a value classification. Using a negative categorisation, the narrator implies that she prefers that people's actions are in line with her morality (3-5), a value classification which may be referred to as 'moral sameness'. By categorising women in some (non-Finnish) cultures as having weak statuses, which she does not understand and does not want for herself (4-5), the writer classifies 'gender equality' as important. Another value classification, which I have marked as 'Finnishness / nationalism', is signalled by the writer taking pride in being a Finn (5). "I try" (5) implicates importance in seeing the good in everyone, which can be marked as a "tolerance" value classification. Tolerance is an assumptive value classification, as it relies on audience familiarity with the value classificatory scheme that it references.

The analysis suggests that value classifications function to separate 'us and our values' from 'them and their values'. The value classifications in Text 1 occur in the recontextualisation of representations of Finnish and other cultures' practices, and work to re-emphasise or reformulate their meanings.

\section{ANALYSING VALUE PROJECTS IN SOCIAL VALUES}

Positioning theorists describe the construction of personhood as a process that involves learning, using, and participating in imbuing the categories that partition the social sphere with meaning (Davies \& Harré, 1990). In constructing value projects, elements comprising social values are oriented to action, as speakers or writers build storylines and qualify the intentions and desires, obligations and prohibitions, and competencies and situational resources that are believed necessary for realising the social value. Value projects texture the meaning of social values by positioning value classifications and content into participant roles, creating value networks and hierarchies. Value projects can be analysed by considering how narrators value the action under consideration 
and the participant roles believed necessary for realising social values (cf. Sulkunen \& Törrönen, 1997).

Participant roles in value projects can be occupied by value classifications, human and nonhuman actors, and events. These can include subjects that express the wanting-to (will and desire) element of action towards obtaining an object of value. Helpers activate the being-able-to (situational resources) and knowing-how-to (competencies and skills) elements of action that are needed for the subject to obtain the object. Anti-subjects hinder realisation of the object, while opponents are anti-subjects' means of hindering. The anti-subjects and opponents symbolise the territory outside of the boundaries of 'us and our values'. The sender motivates, activates and legitimates the subject's action towards obtaining the object, transmitting the having-to (obligation, permission, compulsion) aspect of the action under consideration. The sender role often represents the normative, authoritative or ideological aspect of the story. The receiver is that which benefits from the subject realising the object. (Greimas, 1966/1983, pp. 196-217; 1987, pp. 84-88, 106-120; see also Törrönen, 2014.) These participant roles are relationally defined, imbuing social values and the classifications from which they are built with meaning.

Let us again look at Text 1 , this time in relation to how value projects are formulated. The text builds storylines and outlines an action-oriented value project for reaching goals. Equality and tolerance can be interpreted as the main social values being re-presented in this text. The value classifications and other elements in this excerpt are organised around the recontextualisation of representations of 'us' and 'them' in which these values are nodal. By using first person pronouns throughout the story, the writer positions herself as the main subject. People who think and act differently (2-3) are positioned as anti-subjects to the value project on equality, having their own goal of male dominance. Distinctions are made between the subjugating practices of 'them', the anti-subjects, and the gender equality of 'us' (3-5). These distinctions work to qualify and position Finnishness, moral sameness, and gender equality into helper roles in the project on equality. 
Opponents include the weak status and presumably unequal treatment of women (4-5), and violating the rights of women and children (6). Although an authority figure is not explicit, Finnish culture can be interpreted as an implicit sender (3-5) of these values. At the end of the excerpt, tolerance moves to the participant role of anti-subject, leaving the value project on equality dominant in this story.

The examination of value projects reveals that equality obtains meaning in relation to the situational resources of gender equality that are believed to currently exist inside national boundaries. Maintenance of this equality project requires internalised know-how of Finnishness and moral sameness. The value project on equality is constructed as being under threat by other cultures' perceived practices of male dominance, as well as by unmitigated tolerance. The meanings of the participant roles are formulated in relation to each other, and together work to reconstitute and re-present equality.

\section{ANALYSING VALUE POSITIONING IN SOCIAL VALUES}

The manner in which positioning unfolds is related to how addressers and addressees interpret the topic of conversation, each others' characters and how each is positioning the other (Davies \& Harré, 1990). From a dialogic perspective, reception and production of communication takes place in social spheres in which previously constructed utterances, viewpoints, values, discourses, and representations around the same issue circulate. Speakers and writers to greater and lesser extents engage and align/disalign with these previous utterances, viewpoints and so on and in doing so, negotiate communities of shared values (Martin \& White, 2005, pp. 92-96). Social values therefore emerge and take shape through particular viewpoints (Tsirogianni \& Sammut, 2014). Value positioning is concerned with how narrators interact and engage with value classifications and value projects, and transfer them onto their own and others' identities. This aspect focuses on the interpersonal realm of speech and text production, and deals with the role of dialogism in the implementation of social values. 
Value positioning is open to empirical analysis by examining, for example, what Martin and White (2005, pp. 92-135) refer to as the dialogic positioning resources of engagement. Engagement resources include Disclaim, Proclaim, Entertain and Attribute. For instance the narrator may 'disclaim' a value position by negating it or offering a counter expectation (e.g., I am not racist, but...). This can work to distance particular value positions from the identification. 'Proclaiming' a value position as highly valid or reliable can function to bring it in close to the emerging identity (e.g., Of course this country is a democracy). 'Entertaining' is to suggest that the position is one amongst others, for example by the narrator presenting the utterance as an opinion (e.g., I think that this country is a democracy) or possibility (This country might be a democracy). Entertaining can function to expand the dialogue, making room for other possible value positions and identities than those that are emerging. This can have the effect of constructing a more loosely bordered subject position, or can work for example with disclaim to sharpen boundaries between value positions and identities (I believe that all people are equal, but they do not). Finally, a speaker or writer can 'attribute' value positions to others by reporting their speech or thought (e.g., Americans think that their country is the land of the free). Attributing allows narrators to position values onto others' identities.

These four linguistic resources are used to engage with other viewpoints and therefore all indicate dialogical stances. They often signal clear positionings of values onto the identities of speakers or writers, others, and non-human entities (e.g., the state, the nation, etc.). Non-dialogical utterances, such as bare assertions and assumptions, do not use engagement resources and make no reference to other voices or viewpoints, thus constructing absolute truths and certainty of knowledge. However from a dialogic perspective, all utterances take place in interaction with previous utterances around the same topic (Bakhtin, 1981). Assumptions and assertions can therefore also accomplish value positioning in identification, although the manner in which they do 
so is often complex and opaque (see Martin \& White, 2005, pp. 98-102). In this paper, my exemplars of value positioning focus on utterances that make use of engagement resources.

Let us look at how value positioning is accomplished in Text 1. "I consider" and "I think" (1-2) work to express the writer's belief in equality and to entertain the possibility of other viewpoints. This frames the rest of the text, which is devoted to the writer representing and positioning herself, the audience, and viewpoints on equality. The writer attributes subordinating viewpoints on women to some (non-Finnish) cultures; as external to the Finnish mindset (3-5). These viewpoints are immediately disclaimed ("I don't understand that") and distinguished from her own and Finns' value positions (4-5). This works to restrict the classifications and storylines available to the audience in this text. Another instance of engagement and disclaim appears in the last sentence. "Even though I try [...] I can't help that" (5-6) signals interaction with discourses external to the text and positions obligations to tolerance as problematic in this context. Engagement resources work here towards legitimising the writer's 'near helplessness' with being racist.

In value positioning, subjugating viewpoints were constructed, entertained, attributed to others and disclaimed, thus effectively separating them from the 'Finnish viewpoint' on equality. Engagement resources were used to position the writer and Finns into storylines of 'moral equality', and cultural others into storylines of 'immoral inequality'. Equality is performed in relation to a viewpoint of the moral superiority in Finnishness.

Table 1 shows the classifications, value projects and positionings in the representation and implementation of equality in Text 1 . 
Table 1. Re-presenting and implementing equality and tolerance in Text 1.

\section{VALUE CLASSIFICATIONS and VALUE PROJECTS}

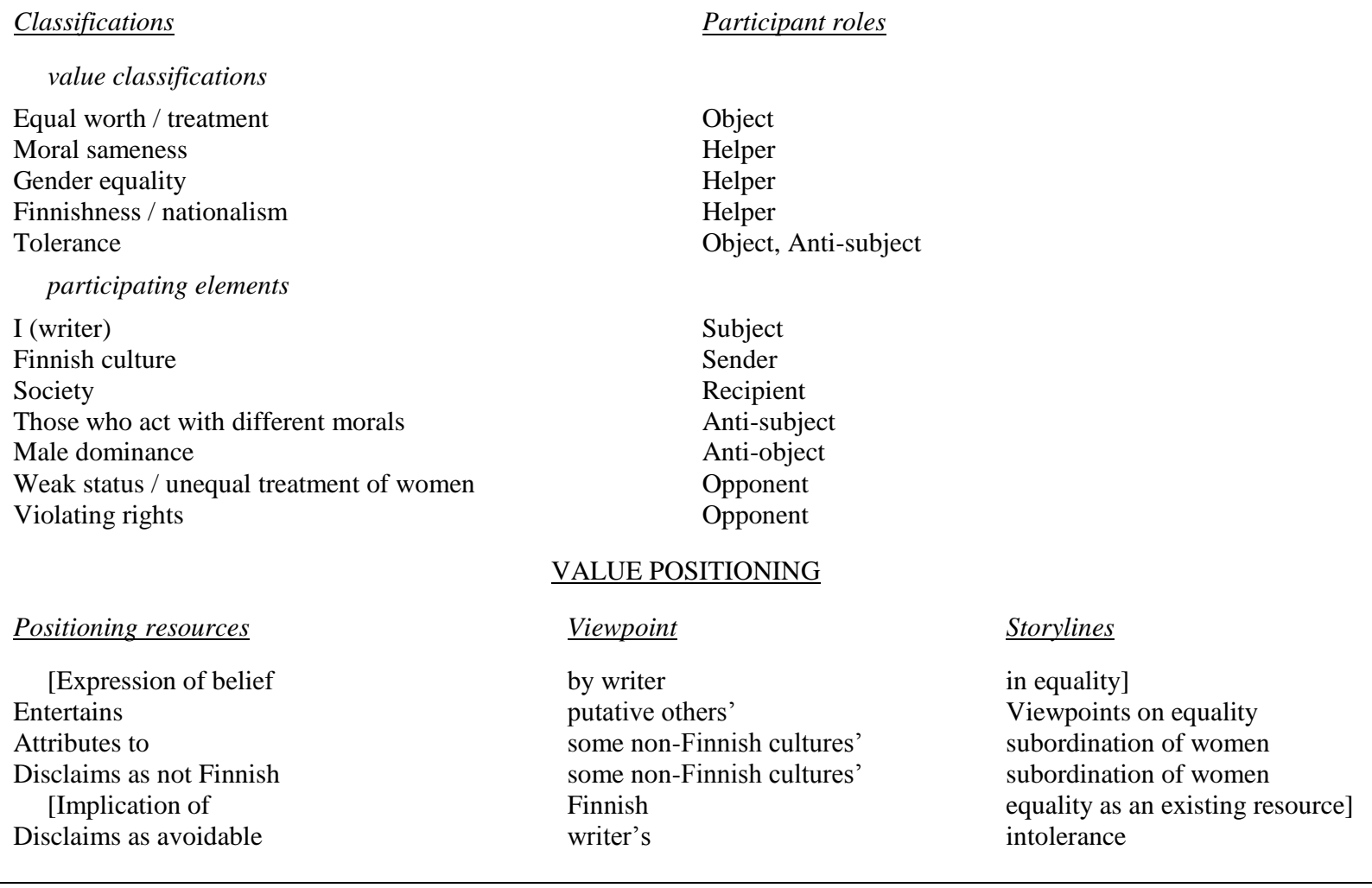

\section{ANALYSING SOCIAL VALUES ACROSS IDENTIFICATIONS}

Patterns in the 'style' of evaluation and stance are related to consistencies in the structural power relations of the social setting, the topic and content of communication, and the manner in which the interpersonal realm of communication unfolds (Martin \& White, 2005, pp. 161-162). These patterns are related to the building and maintenance of cultural- and societal-level identities. In this section I use three empirical examples to show how the framework can be used to explore patterns and inconsistencies in the construction and implementation of social values.

Identifying similarities, differences, patterns and networks in value classifications, projects and positionings is an obvious starting point for an emic delineation of social values. When working with a sizable textual corpus, dominant formulations may become increasingly empirically accessible, as any of the three aspects of social values shows patterns across texts. Marginal formulations may also be detected by examining the ways in which any aspect opposes or 
disengages and deviates from particular formulations of values that are prominent in the data set. For instance in the responses from 304 study participants from which the examples in this article come, equality values are central across texts and contexts. However, the ways in which equality is represented and implemented varies according to the subject position in which it is constructed (see Menard, 2014; Sakki \& Menard, 2014). Such second-cycle analyses can be helpful in understanding the roles of particular value classifications, projects and positionings in maintaining and transforming local orders, sub-systems (e.g., genres) and macrostructures (e.g., discourses or social representations). Thus the framework can be applied by approaching the analysis from a situational, cultural or societal perspective (see Törrönen, 2014).

Let us briefly consider an excerpt that formulates equality in a different way to the previous example. Text 2 was written by a respondent from the random sample.

\section{Text 2} people is our goal. It's a learning situation for everyone! (P206, F)

In this excerpt diversity and tolerance are value classifications taking the form of assumptions, while equality is an explicitly expressed goal and value classification. The social values of tolerance and equality are formulated together in this text and the participant roles in the value projects overlap. Minorities are helpers in the value project on tolerance. The project on equality requires competence in tolerance as a helper for reaching 'our' equality goals. In value positioning, minorities are articulated into storylines about possessing new information that is needed for a diverse society. Society, which is comprised of "us" as students of tolerance who strive towards equality, is articulated into storylines of diversity. Unlike in Text 1, equality is not performed in such a way that 'others' are articulated into storylines of oppression and as perpetrators of inequality. Additionally, equality does not occupy a helper position that is perceived as an existing Finnish resource. Finally, rather than occupying an anti-subject role, tolerance is a necessary helper in the value project on equality. 
Analyses can also focus on how constructions and implementations of different social values work together to build cultural and societal level identities. Text 1 and the next excerpt that I present, Text 3, show similarities in the value projects and positionings that they articulate. They both contribute to the construction of a cultural-level subject position in which various minorities and perceived social and cultural differences occupy anti-subject and opponent participant roles in the construction of different social values. The excerpt is presented as a reminder that imbalances in power relations, which can affect the manner in which social values emerge, occur on many levels. How an individual or group is positioned in relation to norms and laws may be one of those levels. Likewise, in producing texts people may differ in their knowledge about the topic of conversation and in how they receive, draw upon and interpret relevant aspects of history and culture, ideological discourses and hegemonic subject positions. Text 3 was written by a person who described their gender as "a man with a trans background... [whose] personal experience is closer to genderlessness or othergenderness".

Text 3

\begin{abstract}
[....] Diversity increases the atmosphere where everyone is allowed to make personal choices in life, so from this perspective minorities are beneficial in general. On the other hand this applies only to minorities that don't actively strive to decrease other people's freedom of expressing themselves. Different religious groups, such as Muslims, are disadvantageous. Particularly immigrants from countries with different values than Finland's values can perhaps be disadvantageous to society, because an increase in misogyny and homophobia do not increase the wellbeing of the people. [....] (P59, TG)
\end{abstract}

Favourable and unfavourable minorities are distinguished in this excerpt through value classifications related to freedom of choice and self-expression (10-12), Finnishness (13-14), gender and sexual orientation equality (14-15), and societal well-being (14-15). Storylines are built around Finnish society's projects on freedom and societal wellbeing. The value projects are helped by situational resources of non-oppressive minorities and Finnish equalities, and know-how in Finnish values. Similarly to Text 1 , gender equality occupies a temporally present and already existing participant role of helper, located inside Finnish values (13-15). Moreover, Muslims and immigrants from countries with non-Finnish values are similarly presented as anti-subjects, which 
together with misogyny and homophobia (opponents) hinder the project on freedom and societal wellbeing. In value positioning, the phrase "on the other hand" allows the writer to align with Finnish society and 'favourable Finnish national minorities' who are believed to contribute to the value project (11-12). "Perhaps" and "because" work to entertain and disclaim the viewpoint that all minorities are beneficial (13-15). Misogyny, homophobia, and active oppression of freedoms are attributed to and articulated into the viewpoints and identities of religious groups, of Muslims in particular, and of immigrants with non-Finnish values. Social values are conceptualised and implemented in the writer's identity as a favourable Finnish national minority, and contrasted with unfavourable identities of particular 'other' minorities.

The analyses show that social values of equality and freedom emerge in Texts 1 and 3 in the construction of tightly bordered identities. The value classifications, projects and positionings create a division between (representations of) the available resources of Finnish equality and freedom on the one hand, and the perceived deficiencies and excesses of different kinds of outgroups on the other. The Schwartz (1992) model locates equality and freedom in dimensions of 'selftranscendence' and 'openness to change'. Yet the analyses show that these values can be formulated by suppressing other viewpoints. They can be implemented as tools for updating culturally based prejudices. These formulations of equality and freedom thus perform social exclusion and are used as coercive cultural technologies (cf. Butler, 2008).

A comparison of those texts analysed thus far suggests that even though value classifications, value projects and value positionings may be partly the same, in a comprehensive analysis of social values any or all of these aspects may show important differences across texts. Value classifications may show similarities across texts yet occupy oppositional participant roles, as was the case with the role of tolerance for value projects on equality in Texts 1 and 2 . The analyses demonstrate that in analysing a full data set the researcher might focus on particular elements, such as gender equality and minorities, and follow the participant roles that these elements move through 
in the re-presentation of different social values. If equality were to recurrently occupy the role of an existing, available resource or minorities the role of anti-subject, as seen in Texts 1 and 3, we might want to extend our analysis in delineating the function of these recurring participant roles.

Another way of using the framework to approach the data is by asking questions related to social position. The method of sampling used in my study is related to a research question that asks whether there are any particularities in any of the three aspects of social values amongst respondents with an Asperger diagnosis or transgendered experiences. The next and final text that I present in this paper contributes to a cultural-level identification constructed primarily by Aspergerdiagnosed participants and respondents with transgendered experiences. In this subject position, values related to social inclusion and equality are important and often interact or are constructed together, consistently positioning elements such as norms and intolerance of differences as opponents. This identification reveals a struggle in Finland in relation to the participant role of difference and sameness in the meaning of equality (Menard, 2014; Sakki \& Menard, 2014). Text 4 was written by a person with both an Asperger diagnosis and transgendered life experiences.

Text 4

Finnishness has evolved from different groups, such as the Sami people, Jews, homosexuals, Finnish Swedes, and migratory peoples. The world in which we live is such that every now and then a new idea is selected, for example an idea of Finnishness, which starts to be implemented. Different minorities are therefore building blocks of Finnishness, just as bricks are building blocks of a house. The house will be ruined if its building blocks start to be arbitrarily demolished. Likewise, Finnishness becomes impoverished and shrinks if its minorities are forcibly oppressed. Different types of groups of people possess different types of information. Using the information would make life happier and easier and would address the value of the groups. (P9, F)

Value classifications in Text 4 include Finnish cultural diversity (16-19), freedom (20-21), well-being (22), human worth (23) and social recognition (21-23). Finnishness as the recipient and society as the implicit sender together articulate obligations to diversity and social inclusion. The narrator conveys a view of the world from a mostly omnipotent position, but appears in the text once as "we": as part of a larger, diverse community that is comprised of the different groups that constitute Finnish society (16-18). The value projects are organised around society's abilities and competencies, which are the helpers in the project on diversity and social inclusion, the helpers 
being different groups and minorities, new ideas, and using different types of information. In value positioning, the 'we' is articulated into storylines of diversity and different types of groups who all have value and who are potentially holders, recognisers and users of different types of information. The value classifications, projects and positionings in Text 4 formulate diversity and social inclusion in a loosely bordered identity where 'we' is inclusive and 'them' remains mostly unarticulated.

\section{CONCLUSION}

In this article I have demonstrated how social values can be approached in relation to three empirically separable aspects of identification. An analysis of value classifications reveals the boundaries of the good, desirable and acceptable in a particular context. This type of inquiry is important for understanding the categorical foundations from which meanings of social values are built, maintained and disarticulated. In analysing value projects the researcher focus is on the participant roles that elements occupy in storylines, contributing to the overall meaning of the social value. This sort of examination unravels value hierarchies and the elements and roles believed necessary and counter-productive to realising the social value. Delineating value positioning illuminates how classifications and projects are contextually enacted and lived in identification. The analysis exemplifies how narrators, audiences and viewpoints are positioned, included and excluded in social values.

An examination of social values may focus upon value classifications, projects or positionings, or any combination of the three aspects. Researchers interested in social value conceptions may wish to focus their analyses on, for example, value classifications and projects, since these dimensions deal primarily with the realm of representation. Researchers that want to show what is done with social values in identification might then focus upon value positionings. It is important however that research on values includes an awareness that predominant theories and methodologies have taken value meanings for granted. Thus a focus upon value positioning entails 
first knowing which values are classified, what their roles in value projects are, and what elements they work with in positioning narrators and audiences. Likewise, a focus upon value projects implicates first identifying the value classifications and elements that are involved in representational aspects of social values. When focusing upon value classifications it becomes clear that the meaning of the classification can only be interpreted in relation to the rest of the content included in the text, and in relation to the roles that elements take on in storylines. Value classifications, projects and positionings are thus interrelated to the extent that leaving any of them out of the analysis may detract from a comprehensive understanding of the social value; what meanings are conveyed and what they are used for.

All three aspects of social values can only be understood in relation to the genres, available subject positions, cultural context and social macrostructures in which they are embedded. Value classifications, projects and positionings are culturally strained in the sense that their meanings always emerge in relation to previous social practices, tastes, discourses, styles and identifications. Additionally, meanings can and often do become naturalised, take on hegemonic forms or last for long periods. When meanings become naturalised, the dominant classifications, values and collective identities that re-produce them contribute to an ongoing recognition of their 'legitimacy' and failure in recognising their arbitrariness (Bourdieu, 1977, pp. 164-169). Meanings become 'selfevident', taken for granted and undisputed. Such naturalised meanings update, reformulate and sustain hierarchical social orders. With social differentiation and an increasingly pluralistic social sphere, however, naturalised meanings face questioning and a potential rupture. Dominated classes may develop the means and an interest in exposing the arbitrariness of the taken-for-granted meanings that contribute to them being dominated.

Transformations in meaning and social behaviour thus do not come from nowhere. Naturalised meanings also necessitate alternate meanings that exist as marginal or unrealised, yet potential (Hodge \& Kress, 1988). Particularly when naturalised social values are implemented in 
explicitly coercive, exclusionary ways, there will likely be resistance and counter discourses. Moreover, each construction and implementation of values occurs in a specific context of power relations and social differentiation, and from a particular perspective within that context. Variations in place, time, interests, economic and cultural capital, social position in relation to norms and laws, and so on, mean that foundational classifications may be made differently, or usual classifications may 'slip' (cf. Jameson, 1987, p. xvi). Such slippage can disrupt the content of naturalised values, potentially dis-embedding them from the hegemonic discourses and social practices to which they are linked. These disruptions create openings for meaning transformation. Thus despite the cultural common ground from which social values emerge, it is problematic to focus on dominant constructions of social values without exploring critical differences in how they are experienced and lived (cf. Hall, 1990).

In the introduction to this paper, I explained that the framework developed here departs from old-paradigm psychology where values are approached as individual cognitive structures with universal content. Some research conditions may implicate an old-paradigm analysis of abstractly defined values that people strive to prioritise as guiding principles in their lives. However, approaching values exclusively or even primarily as abstractly defined guiding principles could lead to results that are stripped of particular conceptualisations and usages. Also problematic are discourse analyses that present particular values as significant to the findings, while failing to unpack the meanings of those values and what is accomplished with them. Although social values that are important in a particular culture may appear to be conceptualised and used in the same ways by all members of the population, they likely are not. Close readings will often reveal that there are important differences in the way that values are constructed and performed amongst people in different contexts, with different interests or life experiences. Human cognition is embedded in the social, and modern industrialised social spheres are anything but homogenous. Social value constructions and performances are entangled with the interpretation, internalisation and 
embodiment of heterogeneous social spheres through which personhood develops. Values cannot therefore be reduced to independent variables that originate in individual cognition. Their content, structure and functions are not universal. In old-paradigm research on values, particular representations and implementations of values remain disjointed, abstracted, left implicit or are taken for granted.

Studying particular classifications, meanings and implementations of social values in identification can contribute to alternative psychologies that seek to avoid reductionism, overreaching, and gross generalisations in their interpretations and results. The philosophies of psychology and social science that inform the ideas and framework developed in this paper imply that research on social values would be a study of meanings as both internalised social structures and ongoing reformulations that occur in living processes of identification. The approach to values in this paper can contribute to positioning theory through its commentary on the interplay between adopting a position on the one hand, and the construction and implementation of social values on the other. Additionally, and given that social values are presumed to be fundamental to ideologies and social ordering, the framework can contribute to critical research by working towards a means for understanding how particular social value constructions and implementations participate in building or disarticulating ideologies and power imbalances. Taking the meanings of values and their role in building hegemonies for granted in social research can itself be a practice of excluding marginal and potentially transformative viewpoints.

More broadly, a systematic examination of the three aspects of social values confronts some of the problems associated with assuming value meanings in empirical research. Vološinov $(1929 / 1986)$ teaches us that evaluation and the construction of meaning are inseparable and that any attempt to divorce them deprives meaning of its place in living social processes. The framework outlined here contributes to the study of social values as structures and practices that are in a constant state of becoming by focusing upon how they emerge in constructions of identity. 
Examining their conceptualisation in classifications and projects, and their implementation in interpersonal positioning opens an avenue for understanding how social values are shaped in life experiences. It provides options for unravelling how identities are formed in conjunction with emerging social values, and for whom particular meanings of social values are functional. Delineating different formulations of the three aspects of social values offers insight into their role in the ongoing construction, maintenance and transformation of power imbalanced intergroup relations and social realities.

\section{ACKNOWLEDGEMENTS}

I would like to thank Jukka Törrönen for our discussions on various versions of this paper. His contributions to the ideas developed here are significant. I am also grateful to Mark Phillips for proofreading this paper, as well as to Inari Sakki, Anna-Maija Pirttilä-Backman and multiple anonymous reviewers for their helpful comments and criticisms. All shortcomings are the responsibility of the author. This paper was written as part of my doctoral study funded by the Kone Foundation (Koneen Säätiö), a Finnish Doctoral Programme in the Social Sciences (SOVAKO, Sosiaalitieteiden valtakunnallinen jatkokoulutusohjelma) and the Doctoral Programme in Social Sciences at the University of Helsinki.

\section{REFERENCES}

Bakhtin, M. (1981). The dialogic imagination. Austin, TX: University of Texas Press.

Bourdieu, P. (1977). Outline of a theory of practice. Cambridge, UK: Cambridge University Press.

Bourdieu, P. (1984). Distinction: A social critique of the judgement of taste. Cambridge, MA: Harvard University Press.

Butler, J. (2008). Sexual politics, torture, and secular time. The British journal of sociology, 59(1), $1-23$.

Davies, B., \& Harré, R. (1990). Positioning: The discursive production of selves. Journal for the Theory of Social Behaviour, 20(1), 43-63.

Fairclough, N. (2003). Analysing discourse: Textual analysis for social research. London, UK: Routledge. 
Greimas, A. J. (1966/1983). Structural semantics: An attempt at a method. Trans. D. McDowell, R. Schleifer, \& A. Velie. Lincoln, NE: University of Nebraska Press.

Greimas, A. J. (1987). On meaning: Selected writings in semiotic theory. Trans. P. J. Perron \& F. H. Collins. Minneapolis, MN: University of Minnesota Press.

Hall, S. (1990). Cultural identity and diaspora. In J. Rutherford (Ed.), Identity: Community, culture, difference, (pp. 222-237). London, UK: Lawrence \& Wishart.

Hall, S. (1996). Introduction: Who needs "Identity". In S. Hall \& P. Du Gay (Eds.), Questions of cultural identity, (pp. 1-17). London, UK: Sage.

Hall, S. (1997). The spectacle of the 'other'. In S. Hall (Ed.), Representation: Cultural representations and signifying practices (pp. 223-279). London, UK: Sage.

Harré, R. (1999). The rediscovery of the human mind: The discursive approach. Asian Journal of Social Psychology, 2, 43-62.

Harré, R. (2001). The discursive turn in social psychology. In D. Schiffrin, D. Tannen \& H.E. Hamilton (Eds.), The handbook of discourse analysis (pp. 688-706). Oxford, UK: Blackwell Publishers.

Harré, R., \& van Langenhove, L. (1991). Varieties of positioning. Journal for the theory of social Behaviour, 21(4), 393-407.

Harré, R. \& van Langenhove, L. (Eds.) (1999). Positioning theory: Moral contexts of intentional action. Oxford, UK: Blackwell Publishers.

Harré, R., Moghaddam, F. M., Pilkerton Cairnie, T., Rothbart, D., \& Sabat, S. R. (2009). Recent advances in positioning theory. Theory \& Psychology, 19(1), 5-31.

Hodge, R. \& Kress, G. (1988). Social semiotics. New York, NY: Cornell University Press.

Howarth, C. (2006). A representation is not a quiet thing. Exploring the critical potential of social representations theory. British Journal of Social Psychology, 45, 65-86.

Jodelet, D. (1991). Madness and social representations. Hemel Hempstead, UK: Harvester Wheatsheaf.

Lemke, J. (1998). Resources for attitudinal meaning: Evaluative orientations in text semantics. Functions of Language, 5(1), 33-56.

Martin, J. R., \& White, P. R. R. (2005). The language of evaluation. Hampshire, UK: Palgrave Macmillan.

Menard, R. (2014). Doing equality and difference; an examination of value representations and positionings. Manuscript submitted for publication.

Moscovici, S. (1961/2008). Psychoanalysis, its image and its public (D. Macey, Trans.). Cambridge, UK: Polity Press. 
Murray, S. (2008). Representing autism: Culture, narrative, fascination. Liverpool, UK: Liverpool University Press.

Nadesan, M.H. (2005). Constructing autism: Unravelling the 'truth' and understanding the social. New York, NY: Routledge.

Osteen, M. (2007). Autism and representation. In M. Osteen (Ed.), Autism and representation (pp. 1-47). Milton Park, UK: Routledge.

Sakki, I., \& Menard, R. (2014). Ankkurointi, naturalisointi ja muutos sosiaalisten representaatioiden tutkimuksessa. In M. Ahokas, S, Ahola, L. Myyry \& I. Sakki (Eds.), Arkiajattelu, tieto ja oikeudenmukaisuus. Helsinki, Finland: Gaudeamus.

Schwartz, S. H. (1992). Universals in the content and structure of values: Theoretical advances and empirical tests in 20 countries. In M. Zanna (Ed.), Advances in experimental social psychology: Vol. 25 (pp. 1-65). San Diego, CA: Academic Press.

Sowińska, A. (2013). A critical discourse approach to the analysis of values in political discourse: The example of freedom in President Bush's State of the Union addresses (2001-2008). Discourse \& Society, 24(6), 792-809.

Sulkunen, P., \& Törrönen, J. (1997). The production of values: The concept of modality in textual discourse analysis. Semiotica, 113, 43-69.

Transgender Europe. (2013). Trans rights europe map and index, May 2013. Downloaded from http://www.tgeu.org/sites/default/files/Trans_Rights_Europe_Map_2013\%20_at_a_glance.p df (accessed 23 October 2013).

Tsirogianni, S., \& Gaskell, G. (2011). The role of plurality and context in social values. Journal for the Theory of Social Behaviour, 41, 441-465.

Tsirogianni, S., \& Sammut, G. (2014). Transitivity analysis: A framework for the study of social values in the context of points of view. British Journal of Social Psychology, 53(3), 541556. doi: 10.1111/bjso. 12047

Törrönen, J. (2001). The concept of subject position in empirical social research. Journal for the Theory of Social Behaviour, 31(3), 313-329.

Törrönen, J. (2003). On the road to serfdom? An analysis of Friedrich Hayek's socio-political manifesto as a pending narrative. Social Semiotics, 13(3), 305-320.

Törrönen, J. (2014). Situational, cultural and societal identities: Analysing subject positions as classifications, participant roles, viewpoints and interactive positions. Journal for the Theory of Social Behaviour, 44(1), 80-98. doi: 10.1111/jtsb.12029

van Dijk, T. A. (1998). Ideology; a multidisciplinary approach. London, England: Sage. 
van Langenhove, L., \& Harré, R. (1994). Cultural stereotypes and positioning theory. Journal for the Theory of Social Behaviour, 24, 359-372.

Vološinov, V. N. (1929/1986). Marxism and the Philosophy of Language (L. Matejka \& I. R. Titunik, Trans.). London, England: Harvard University Press.

${ }^{1}$ People reached through a random sample were obtained from the Finnish Population Register Centre $(\mathrm{N}=240$, aged 16 to 70 years, 155 female, 85 male). People with transgendered life experiences $(\mathrm{N}=40$, aged 17 to 46 years, 9 female/MtF, 15 male/FtM, 16 transgender) and people diagnosed with Asperger's syndrome ( $\mathrm{N}=24$, aged 16 to 48 years, 15 female, 8 male, 1 Transman) were contacted through local support organisations and online Finnish discussion forums. Participants with transgendered life experiences are classified according to their self-categorised gender identity. F/MtF designates those who were born male, had or were seeking treatments, and identify as female or a transwoman. M/FtM designates those who were born female, had or were seeking treatments, and identify as male, a transman or transmasculine. TG designates those who were born male or female and who identify as transgender, gender neutral or androgynous. Two people who responded as Aspergerdiagnosed participants have also had transgendered life experiences. The first is a person who had a male name and a male sex categorisation when responding in the study presented in this paper. In the second study of my research project two years later, she had since transitioned and taken a female name and gender identity. This person is therefore classified here as a female Asperger participant. The second of these two participants described himself as a transman. Although these two respondents have both transgendered life experiences and an Asperger's diagnosis, I have classified them as only Asperger-diagnosed participants, so as not to confuse the reader regarding the total number of participants reported in this study.

${ }^{2}$ People with transgendered life experiences violate normative sex and gender classifications. For example in the 34 European countries that have provisions for legal recognition of a gender other than that which was assigned at birth, a diagnosis is required in order to gain that recognition and receive transgenderrelated healthcare. Additionally in 24 of the 34 countries just mentioned, Finland included, those that have received a diagnosis are required to be surgically sterilised (Transgender Europe, 2013). People diagnosed with Asperger's syndrome violate norms of social interaction. While diagnostic criteria describe Asperger's as a neurologically-based developmental disorder affecting social interaction, critical approaches suggest that the diagnosis itself has evolved at least in part from the normativisation of interaction styles (Nadesan, 2005; Osteen, 2007). Alternative discourses on autism approach the 'autistic way of being' as a comprehensible self-expression style (Murray, 2008). In this study I approach the textual responses from participants with an Asperger diagnosis as accounts from people 
with particular life experiences rather than, for example, from people with disabilities in social interaction.

${ }^{3}$ The interviews were conducted in Finnish and translated into English by a Finnish translator and bilingual (Finnish and English) Finnish colleague. Different phases of the analyses were conducted on both the translated and original Finnish texts. I conducted discourse analyses on the original Finnish texts. The original data in Finnish is available upon request. 